\title{
Joining of alumina by using polymer blend method
}

\author{
Ken'ichiro KITA, ${ }^{\dagger}$ Naoki KONDO, Yasuhisa IZUTSU* ${ }^{*}$ and Hideki KITA \\ National Institute of Advanced Industrial Science and Technology (AIST), \\ 2266-98 Shimo-shidami, Moriyama-ku, Nagoya 463-8560, Japan \\ *Stereo Fabric Research Association, 2266 Shimo-shidami, Moriyama-ku, Nagoya 463-8560, Japan
}

This paper describes a novel experiment involving the joining of alumina using a polymer blend method and Al foil. Alumina pieces were dipped into a polymer blend containing polycarbosilane and polymethylphenylsiloxane, which is a kind of polysiloxane. After curing and ceramization of the polymer on the alumina pieces, the pieces sandwiching Al foil were heated under vacuum at $1073 \mathrm{~K}$. The samples near the center of the joining area (SC samples) were mainly composed of metal $\mathrm{Si}$ without any cracks, and their average tensile strength was very high, approximately $252 \mathrm{MPa}$. On the other hand, the samples on the periphery of the joining area (SP samples) were mainly composed of a carbon-rich substance such as aluminum carbide with deep cavities, and their average tensile strength was poor in comparison to the SC samples, approximately 56.9 MPa.

(C2012 The Ceramic Society of Japan. All rights reserved.

Key-words : Polycarbosilane, Polymethylphenylsiloxane, Alumina, Joining, Aluminum

[Received February 14, 2012; Accepted August 10, 2012]

\section{Introduction}

Increasing of the environmental impact is one of major global problem. ${ }^{1,2)}$ We are considering optimal solutions to the problem and a potential solution appears to be the substitution of ceramics for large size of heavy metal products under extreme environmental conditions such as high temperatures and corrosive atmosphere from the viewpoint of energy efficiency. ${ }^{3)}$ This solution will also help to reduce of the use of rare metals because such products often include rare metals. ${ }^{4), 5)}$ However, the ceramics that can be substituted for heavy metal products such as huge tube, turbine, precision positioning stages in semiconductor making equipment, etc. are difficult, because production of the large ceramics requires large furnace that can enclose the ceramics of large size completely.

The assembly of small hollow ceramic units is proposed as a solution to this problem. ${ }^{6}$ ) By assembling and joining of these units, the large-sized ceramics can be produced without large furnaces. Moreover, a broken ceramic unit can be replaced by new one, which contributes maintenance process.

In a previous study, we attempted to join ceramics using a precursor polymer only. ${ }^{7)}$ However, the tensile strength of the joined ceramic in that study was not high because of inner cracks and exfoliation of the joining layer. ${ }^{8), 9)}$ It was caused by gas generation derived from precursor polymer during ceramization. ${ }^{10), 11)}$

As a joining method without gas generation, we also attempted using a direct reaction between silicon oxide derived from polymer precursor and Al foil. ${ }^{12)}$ From the view point of thermodynamics, metal $\mathrm{Si}$ and alumina are expected to be generated [see formula (1)].

$$
\begin{aligned}
\mathrm{SiO}_{2}(\mathrm{~s})+4 / 3 \mathrm{Al}(\mathrm{l}) \rightarrow \mathrm{Si}(\mathrm{s})+2 / 3 \mathrm{Al}_{2} \mathrm{O}_{3}(\mathrm{~s}) \\
\Delta_{\mathrm{f}} \mathrm{G}^{\circ}=-200.3 \mathrm{~kJ} / \mathrm{mol}
\end{aligned}
$$

This process shows that a novel ceramic joining method by metal $\mathrm{Si}$ would be obtained at relatively low temperature, while the usual method of ceramic joining by using metal Si has need

\footnotetext{
Corresponding author: K. Kita; E-mail: kita.kennichiro@aist.go.jp
}

of heating at more than $1673 \mathrm{~K}$ which is melting point of metal $\mathrm{Si}^{13)}$

This joining method has the same background as active filler method, which was proposed by P. Greil. ${ }^{14)}$ In terms of active filler method, Colombo et al. used Al-Si metal filler for joining silicon carbide ( $\mathrm{SiC}$ ) composite, and Narisawa et al. investigated of the phases derived from silicon resin and metal Al. ${ }^{15), 16)}$ As shown these reports, the direct reaction between silicon oxide (or silicon oxycarbide) and Al are effectively accelerated in the cases of polymer precursor method. ${ }^{17)}$

In the joining process using PCS and $\mathrm{Al}$ foil, high temperature oxidation process of $\mathrm{SiC}$ layer on alumina is necessary. ${ }^{18)-23 \text { ) }}$ Blend of polysiloxane to PCS is promising to skip the high temperature oxidation process, because siloxane network intrinsically contains a much amount of oxygen as compared with PCS. ${ }^{24)}$

Polymethylphenylsiloxane (PMPhS) (whose chemical structures are shown in Fig. 1) were selected to modify PCS, because the solubility between PCS and PMPhS is very high. ${ }^{25)}$ It appears that a polymer blend containing PCS and PMPhS is a good precursor polymer for the alumina joining method which uses direct reaction between silicon resin and $\mathrm{Al}$ foil.

In this study, alumina joining by the use of polymer blend containing PCS and PMPhS was attempted to confirm whether this joining method can reduce crack in the joining area, decrease temperature in process, and increase its tensile strength such as in PCS and Al foil. In addition, the joining layer in the joined alumina was also investigated to clarify the behavior of the polymer and $\mathrm{Al}$ during this joining method.

\section{Experimental procedure}

The outline of this experiment is shown in Fig. 2. Bulk alumina supplied by Mitsui Kinzoku Corporation was cut into pieces (length: $20 \mathrm{~mm}$, width: $30 \mathrm{~mm}$, and height: $20 \mathrm{~mm}$ ). The purity of these pieces was greater than $99.9 \%$, and the grain size of each alumina piece was approximately $2 \mu \mathrm{m}$. One surface of each alumina piece with an area of $600 \mathrm{~mm}^{2}$ was abraded. The following investigations were carried out on the abraded surfaces. 
<smiles>C[SiH](C)CC1(C)CCCCC1</smiles>

Polycarbosilane (PCS)

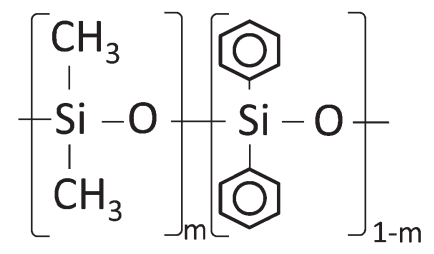

Polymethylphenylsiloxane(PMPhS)

Fig. 1. Chemical Structures of polycarbosilane and polymethylphenylsiloxane.
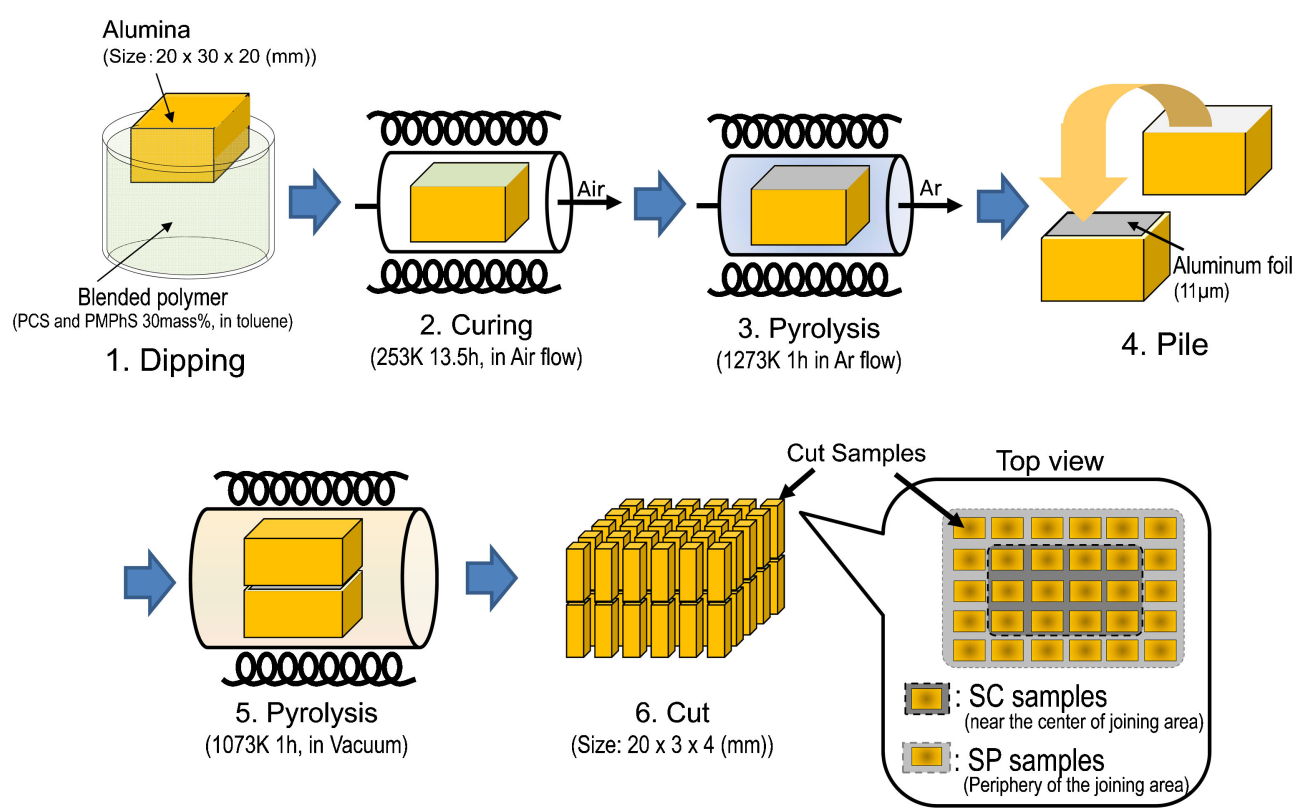

Fig. 2. (Color online) Outline of this experiment.

Commercial PMPhS (KF-54, Shin-Etsu Chemicals Co. Ltd., Japan) without additional purification and PCS (NIPUSI-Type A, Nippon Carbon, Japan) were dissolved into cyclohexane, the dissolved polymer was freeze-dried, and the white powdered polymer blend was thus obtained. The blend ratio of $\mathrm{PMPhS}$ in the polymer blend was 30 mass $\%$. The obtained powder was dissolved in dehydrated toluene.

The abraded lower parts of the alumina pieces were dipped in the toluene solution a few times and then dried. After this process, the alumina pieces were cured at $253 \mathrm{~K}$ for $13.5 \mathrm{~h}$ under air flow and pyrolyzed at $1273 \mathrm{~K}$ for $1 \mathrm{~h}$ under Ar flow. The curing and pyrolysis induced polymer ceramization, without considerable mass reduction of the alumina pieces.

After heating, two of the pieces were selected for experimentation. An Al foil with a thickness of approximately $11 \mu \mathrm{m}$ was placed between the abraded surfaces of the pieces and the pieces were heated at $1073 \mathrm{~K}$ for $2 \mathrm{~h}$ in vacuum.

These samples were then investigated by carrying out scanning electronic microscopy (SEM; JEM-5600, JEOL, Japan), energy dispersive X-ray spectroscopy (EDS; JEM-5600, JEOL, Japan), and X-ray diffraction (XRD; RINT2500, Hitachi Ltd., Japan) for observing their joining areas. In addition, a 4-point bending test was carried out to estimate their tensile strengths.

\section{Results and discussion}

As mentioned in Fig. 2, these cut samples were classified into two types: samples near the center of the joining area, and samples on the periphery of the joining area. The reason for this classification is that a previous report shows differences in joining areas between the samples near the center of the joining area and those on the periphery of the joining area. ${ }^{26)}$ Hereafter, the samples near the center of the joining area are referred to as "SC samples", and the samples on the periphery of the joining area are referred to as "SP samples".

Figure 3 shows the SEM image and EDS mappings of the cross section of the joining area of the SC sample after heating at $1073 \mathrm{~K}$. The SEM image shows that the width of the joining area was approximately $40 \mu \mathrm{m}$, and there was no exfoliation between the joining area and alumina. However, two types of areas existed in this area, which can be deduced from the observation of a whitish and a gray area. Moreover, the EDS mappings show that two types of areas appeared in the joining area. One area showed only a strong Si peak, and the other area showed a strong Al peak, a weak Si peak, and a very small amount of carbon. Furthermore, in the SEM image, the area corresponding to that showing only a strong Si peak was completely overlapped by the gray area, and the area corresponding to that showing a strong $\mathrm{Al}$ peak and a weak Si peak was completely overlapped by the whitish area. The previous study of alumina joining by using PCS only show that mullite consists the joining layer, and it was caused by PCS decomposition and reaction between alumina. ${ }^{7)} \mathrm{Si}, \mathrm{Al}$ and oxygen atoms were coexisted in the layer derived from PCS and Al foil and it was caused by diffusion of them. ${ }^{18)}$ 

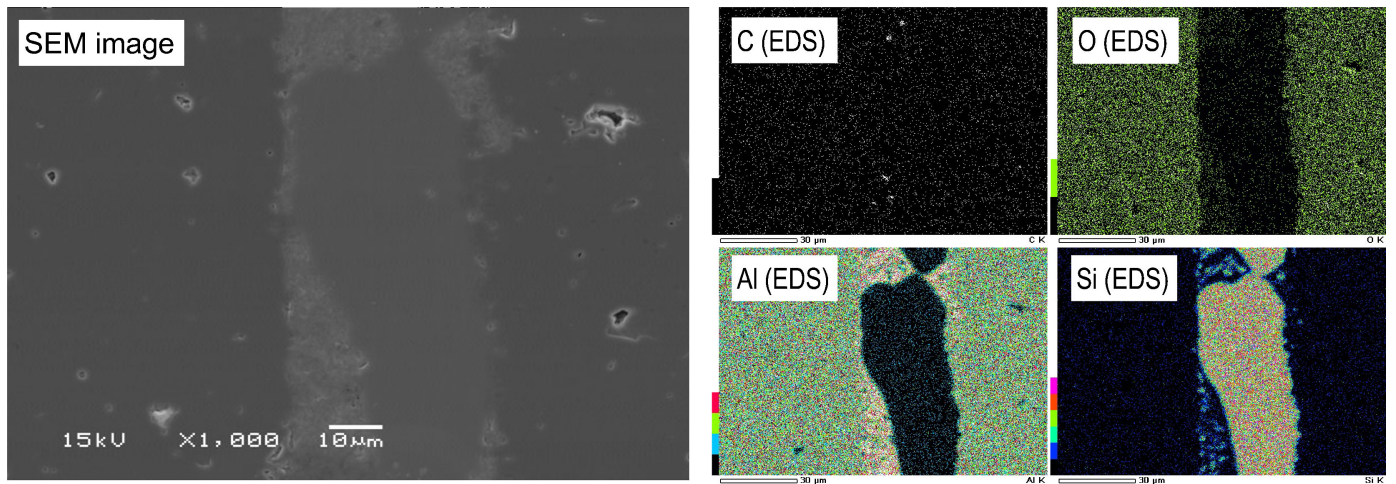

Fig. 3. (Color online) SEM image and EDS mappings of the cross section of the joining area of SC sample (Left: SEM image, Right: EDS mappings).
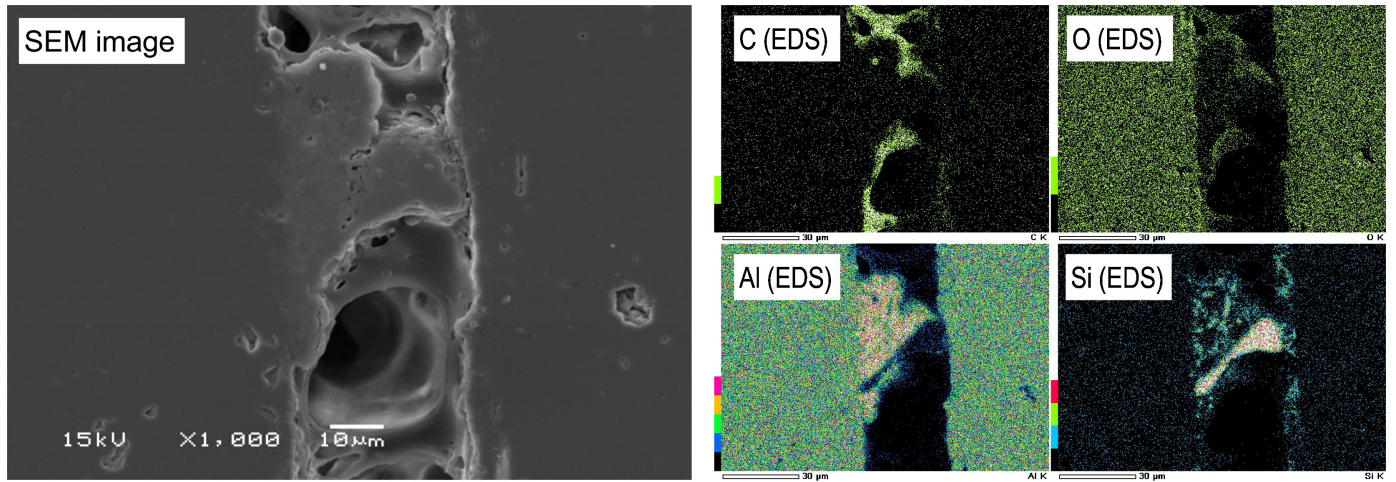

Fig. 4. (Color online) SEM image and EDS mappings of the cross section of the joining area of SP sample (Left: SEM image, Right: EDS mappings).

On the other hand, Fig. 4 shows the SEM image and EDS mappings of the cross section of the joining area of the SP sample after heating at $1073 \mathrm{~K}$. The SEM image shows that the width of the joining area was approximately $30 \mu \mathrm{m}$ and two types of areas were also observed in this joining area. However, the type of distribution of elements in this joining area was not the same as that in the joining area of the SC sample. The joining area of the SC sample showed no cavities, whereas that of the SP sample showed deep cavities. EDS mappings of the joining area without any cavities were very similar to those of the joining area of the SC sample, that was divided into the area showing only a strong $\mathrm{Si}$ peak and the area showing a strong $\mathrm{Al}$ peak and a weak $\mathrm{Si}$ peak. EDS mappings of the joining area with deep cavities showed strong $\mathrm{C}$ and $\mathrm{O}$ peaks relatively. This observation reveals that the joining area of SP samples included a carbon-rich area and deep cavities. Although the similar cracks were also observed in the previous study of the alumina joining by using PCS and Al foil, it was existed in not only the periphery of the joining area but also the center of the joining area. ${ }^{18)}$ Considering the result of these figures, this joining method using $\mathrm{PCS}-\mathrm{PMPhS}$ polymer blend and $\mathrm{Al}$ foil seemed to be an individual alumina joining method in spite of the similar process of alumina joining by using PCS and Al foil.

To investigate the crystallized structures in the joining area, XRD of the joining area was carried out, and the measured patterns are shown in Fig. 5. The patterns of both the SC and the SP samples included the strong peaks corresponding to alumina (corundum) observed at 25.6, 35.1, 37.5, 43.3, 52.5, 57.5, 66.5, and $68.2^{\circ}$; the peaks corresponding to metal $\mathrm{Al}$ at 38.3 and $44.5^{\circ}$; and the peaks corresponding to metal $\mathrm{Si}$ at 28.4 and $46.2^{\circ}$. Strong

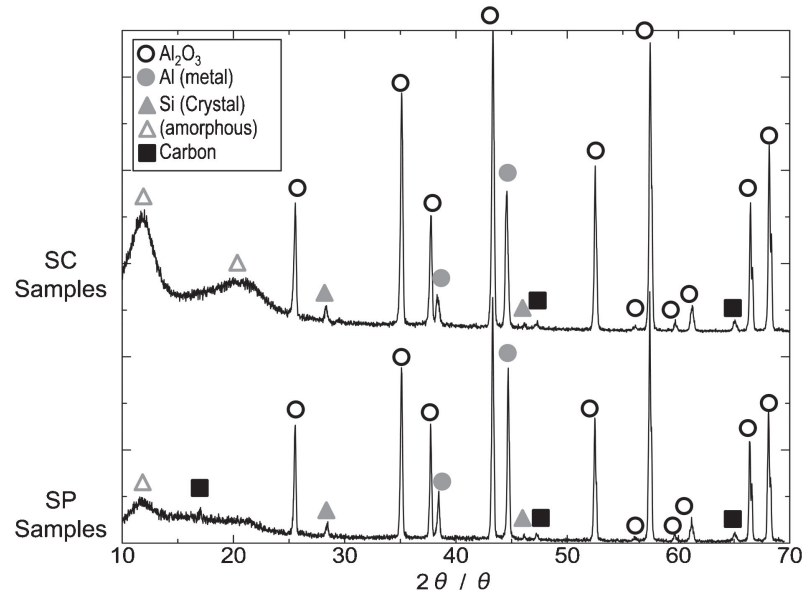

Fig. 5. XRD spectra of the joining area of inner sample and outer samples.

peaks corresponding to alumina were thought to be derived from base material of alumina. Considering of the results of Figs. 3-5, it is reasonable to think that metal $\mathrm{Al}$ and $\mathrm{Si}$ were existed in the joining areas in both samples. However, it was shown that $\mathrm{Si}$ peaks observed in the SC sample were minor, while the EDS analysis indicated the existence of elemental $\mathrm{Si}$.

A part of Si may exist as amorphous phase of $\mathrm{Si}-\mathrm{C}$ or $\mathrm{Si}-\mathrm{O}-\mathrm{C}$ with broad peaks at 12 and $21^{\circ}$ shown in XRD patterns. ${ }^{27)-30)}$ It must be, however, also paid attention that XRD analysis is intrinsically not appropriate for quantitative estimation of phases 


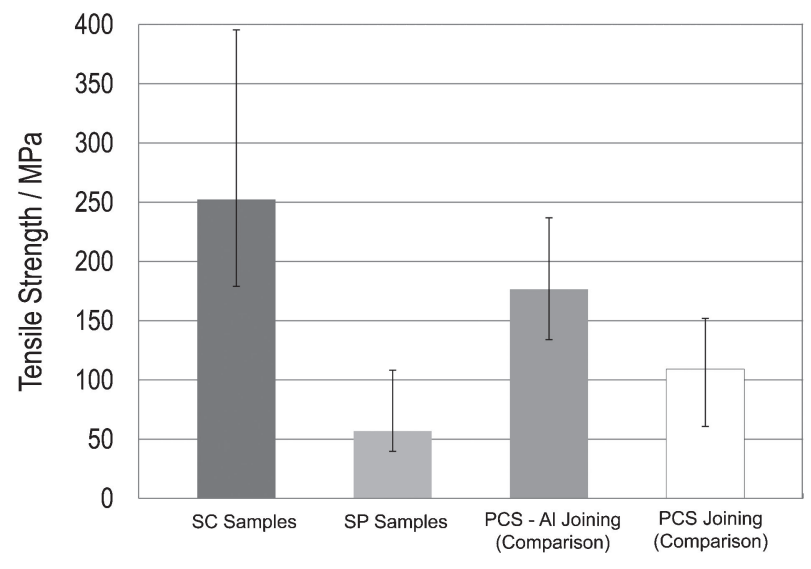

Fig. 6. The result of the 4 point bending tests of these samples.

Table 1. Detail result of the 4 point bending tests

(Unit: $\mathrm{MPa}$ )

\begin{tabular}{lcccc}
\hline \multicolumn{1}{c}{ Sample } & $\begin{array}{c}\mathrm{SC} \\
\text { samples }\end{array}$ & $\begin{array}{c}\mathrm{SP} \\
\text { samples }\end{array}$ & $\begin{array}{c}\mathrm{SiO}_{2}-\mathrm{Al} \text { joining } \\
\text { (Comparison) }\end{array}$ & $\begin{array}{c}\text { PCS joining } \\
\text { (Comparison) }\end{array}$ \\
\hline Sample number & 6 & 6 & 12 & 10 \\
Average & 252 & 56.9 & 177 & 109 \\
Maximum strength & 396 & 108 & 237 & 152 \\
Minimum strength & 179 & 39.8 & 134 & 60.8 \\
\hline
\end{tabular}

of heterogeneous structures. In joining area, the joining areas by dense Si appear to be covered by other layer on both sides. ${ }^{31), 32)}$ From the results obtained from Figs. 3 and 4, it was concluded that the joining area of the SP sample included a considerable amount of carbon and a less amount of metal Si than the joining area of the SC sample.

The tensile strengths of these samples were estimated by carrying out a 4-point bending test. The results are shown in Fig. 6, and related detailed data are summarized in Table 1. The results of the previous joining methods were added for comparison in these results. ${ }^{7), 18)}$ In the case of SC and SP samples, 6 samples of each sample were used in this test. The average flexural strength of the SC sample was $252 \mathrm{MPa}$ and that of the SP sample was $56.9 \mathrm{MPa}$. Furthermore, the maximum and minimum flexural strengths of the SC sample were respectively 396 and $179 \mathrm{MPa}$, and those of the SP sample were respectively 108 and $39.8 \mathrm{MPa}$. These results reveal that the tensile strength of SC sample improved and that of SP sample was made worse in comparison to those of previous studies.

Figure 7 shows the Weibull distribution of the results of the 4point bending tests performed on these samples. These plots were calculated by the median rank method, which is a very commonly used method in similar studies. The Weibull modulus of the SC sample was 3.18 and that of the SP sample was 1.95. This indicates that the tensile strength of the joining area of the SC sample is more evenly distributed than that of the joining area of the SP sample. This crucial difference can be attributed to the fact that the joining area of the SC sample mainly consisted of metal $\mathrm{Si}$ and metal Al without any cracks, and the joining area of the SP sample mainly consisted of a carbon-rich phase with cavities.

Measured flexural strength of SC sample is higher than those of joint derived from oxidation of $\mathrm{SiC}$ layer on alumina which was previously reported. ${ }^{18)}$ It means that wetting between $\mathrm{Al}$ melt and $\mathrm{SiCO}$ ceramics derived from polymer blends is improved and Eq. (1) proceeds effectively. Such high strength, however, is

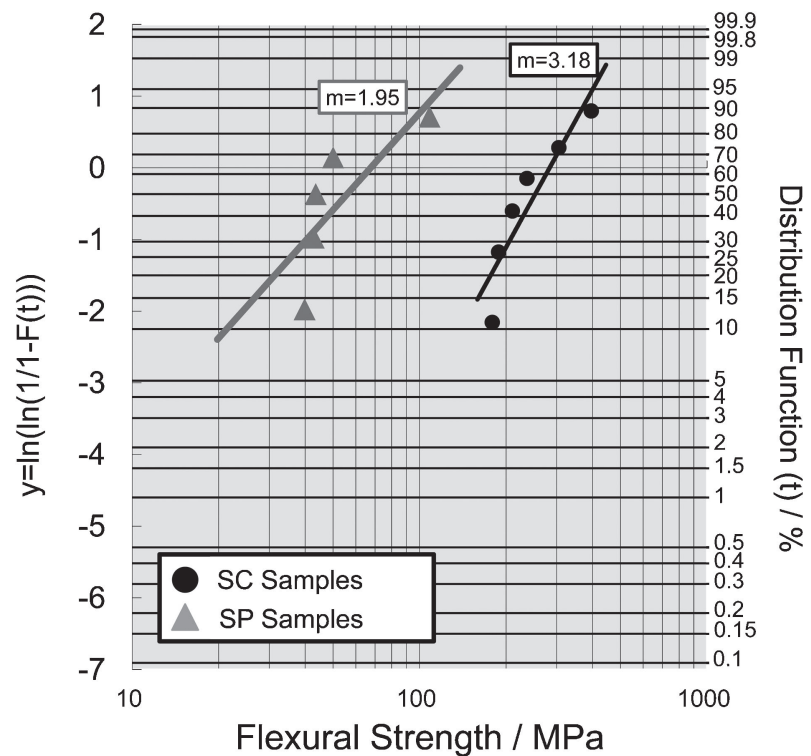

Fig. 7. Weibull distribution of the 4 point bending tests of the samples.

compensated by low strength of peripheral SP samples with cavities. Perhaps, the polymer blends contain excess carbon beyond an effective value. Such excess carbon was probably converted to $\mathrm{Al}_{4} \mathrm{C}_{3}$ mainly at $\mathrm{SP}$ sample area and the possibility of the existence of it was already pointed out in the previous paper. ${ }^{18)}$ Since the carbon in PMPhS exists as phenyl groups, cavity formation by hydrocarbon gas evolution also becomes dominant at SP sample area. Incorporation of polysiloxane in PCS was effective to skip the high temperature oxidation process of the formed surface layers. In order to improve wetting with reducing peripheral $\mathrm{Al}_{4} \mathrm{C}_{3}$ formation and cavities, however, precise control of carbon and oxygen in the starting polymer blends are necessary.

\section{Conclusion}

In the joining method of alumina, by using Al foil and a polymer blend containing PCS and PMPhS, the central area was mainly joined by metal $\mathrm{Si}$ without the appearance of any cracks. Metal Si was derived from the reduction between silicon oxide (or silicon oxycarbide) and metal Al. On the other hand, the peripheral area was mainly occupied by a carbon-rich substance such as $\mathrm{Al}_{4} \mathrm{C}_{3}$ with deep cavities, which seemed to be obtained by the reaction between metal $\mathrm{Al}$ and carbon derived from the polymer. These resulted in the differences between the average tensile strengths of the joining areas of the SC and SP samples. The average tensile strength of the joining area of the SC sample was approximately $252 \mathrm{MPa}$ and that of the SP sample was approximately $56.9 \mathrm{MPa}$.

Acknowledgement This research was supported by METI and NEDO, Japan, as part of the Project for the Development of Innovative Ceramics Manufacturing Technologies for Energy Saving.

\section{References}

1) M. D. Bovea, E. Diaz-Albo, A. Gallado, F. J. Colomer and J. Serrano, Mater. Des., 31, 35-41 (2010).

2) N. Tikul and P. Srichandr, J. Ceram. Soc. Japan, 118, 887-894 (2010).

3) H. Kita, H. Hyuga and N. Kondo, J. Eur. Ceram. Soc., 28, 1079-1083 (2008). 
4) S. Taniguchi, K. Uesaki, Y.-C. Zhu, H.-X. Zhang and T. Shibata, Mater. Sci. Eng., A249, 223-232 (1998).

5) P. Pérez, J. A. Jiménez, G. Frommeyer and P. Adeva, Mater. Sci. Eng., A284, 138-147 (2000).

6) H. Kita, H. Hyuga, N. Kondo and T. Ohji, Key Eng. Mater., 403, 261-264 (2009).

7) K. Kita, N. Kondo, Y. Izutsu and H. Kita, J. Ceram. Soc. Japan, 119, 658-662 (2011).

8) S. Yajima, K. Okamura, T. Shishido, Y. Hasegawa and T. Matsuzawa, Am. Ceram. Soc. Bull., 60, 253 (1981).

9) P. Colombo, V. Sglavo, E. Pippel and A. Donato, J. Mater. Sci., 33, 2405-2412 (1998).

10) E. Carberry and R. West, J. Organomet. Chem., 66, 582-583 (1966).

11) Y. Hasegawa, J. Mater. Sci., 24, 1177-1190 (1989).

12) T. Okutani, J. Metal. Mater. Mineral, 19, 51-59 (2009).

13) S. Suyama, T. Kameda and Y. Itoh, Diamond Relat. Mater., 12, 1201-1204 (2003).

14) P. Greil, J. Am. Ceram. Soc., 78, 835-848 (1995).

15) P. Colombo, B. Riccardi, A. Donato and G. Scarinci, J. Nucl. Mater., 278, 127-135 (2000).

16) M. Narisawa, H. Kado, H. Mabuchi and Y.-W. Kim, Appl. Organomet. Chem., 24, 612-617 (2010).

17) L. Toma, C. Fasel, S. Lauterbach, H.-J. Kleebe and R. Riedel, J. Eur. Ceram. Soc., 31, 1779-1789 (2011).

18) K. Kita, N. Kondo, Y. Izutsu and H. Kita, J. Ceram. Soc. Japan, 120, 138-142 (2012).
19) Y. Hasegawa, M. Iimura and S. Yajima, J. Mater. Sci., 15, 720728 (1980).

20) T. Shimoo, H. Chen and K. Okamura, J. Mater. Sci., 29, 456463 (1994)

21) M. Takeda, A. Urano, J. Sakamoto and Y. Imai, J. Nucl. Mater., 258-263, 1594-1599 (1998).

22) T. Shimoo, K. Okamura and H. Takeuchi, J. Mater. Sci., 38, 4973-4979 (2003).

23) R. S. Hay, Appl. Phys., 111, 63527 (2012).

24) C. C. Currie and B. F. Smith, Ind. Eng. Chem., 42, 2457-2462 (1950).

25) K. Kita, M. Narisawa, A. Nakahira, H. Mabuchi, M. Sugimoto and M. Yoshikawa, J. Mater. Sci., 45, 3397-3404 (2010).

26) M. Eslamian, J. Rak and N. Ashgriz, Powder Technol., 184, 11-20 (2008)

27) Y. Hasegawa and K. Okamura, J. Mater. Sci., 18, 3633-3648 (1983).

28) R. J. P. Correiu, P. Gerbier, C. Guerin and B. Hammer, Chem. Mater., 12, 805-811 (2000).

29) M. Narisawa, R. Sumimoto, K. Kita, H. Kado, H. Mabuchi and Y.-W. Kim, J. Appl. Polym. Sci., 114, 2600-2607 (2009).

30) X. Yuan, S. Chen, X. Zhang and T. Jin, Ceram. Int., 35, 32413245 (2009).

31) K. Laaziri, S. Kycia, S. Roorda, M. Chicoine, J. L. Robertson, J. Wang and S. C. Moss, Phys. Rev. B, 60, 520-533 (1999).

32) A. Vivas Hernandez, T. V. Torchynska, A. L. Quintos Vazquez and Y. Matsumoto, J. Phys. Conf. Ser., 61, 1231-1235 (2007). 